\title{
Hastane Patojenlerinin Ticari Uçucu Yağlara Karşı Hassasiyetlerinin Belirlenmesi
}

\author{
Determination of Sensitivity of Hospital Pathogens Against Commercial Essential Oil
}

Tuğça BİLENLER*a ${ }^{\mathrm{a}}$, İncilay GÖKBULUT ${ }^{\mathrm{b}}$

İnönü Üniversitesi, Mühendislik Fakültesi, Gıda Mühendisliği Bölümü, 44280, Malatya

\begin{tabular}{llll}
\hline •Geliş tarihi / Received: 08.03.2019 • Düzeltilerek geliş tarihi / Received in revised form: 03.07.2019 • Kabul tarihi / Accepted: 17.07 .2019 \\
\hline
\end{tabular}

\begin{abstract}
$\ddot{O} z$
Hastaneler, tanı ve tedavi amaçlı antibiyotiklerin yoğun şekilde kullanıldığı dolayısıyla bakteri ve mayaların direnç kazanımlarının ve dirençli suşların yayılımının en sık yaşandığı ortamlardır. Antibiyotik direncine sahip mikroorganizmaların sayısındaki artış, mikroorganizma kaynaklı enfeksiyon tedavilerini olumsuz etkilemekte ve ilaçlara alternatif olarak tıbbi bitkilerin (ekstrakt ve uçucu yağlarının) kullanımı gündeme gelmektedir. Çalışmada, hastane ortamında gelişen dört patojen bakteri (Staphylococcus aureus, Bacillus cereus, Escherichia coli ve Salmonella spp.,) ve bir mayaya (Candida albicans) karşı tıbbi amaçlı kullanılan, ticari on bir bitki uçucu yağının antimikrobiyal aktivitelerini belirlemek amaçlanmıştır. Çalışmada broth dilüsyon ve oyuk agar teknikleri kullanılmıştır. Bergamot (Citrus bergamia) ve Isırgan otu (Urtica dioica) uçucu yağlarının minimum inhibisyon konsantrasyonlarının (MIK) Gram pozitif bakterilere karşı oldukça düşük olduğu $(62.5 \mu \mathrm{L} / \mathrm{mL})$, Gram negatif bakteriler üzerinde ise test edilen on bir bitki uçucu yağının antimikrobiyal aktivitesinin orta düzeyde (125-500 $\mu \mathrm{L} / \mathrm{mL})$ kaldığ saptanmıştır. Adaçayı (Salvia officinalis), Bergamot, Çam terebentin (Pinus terebenthinae), Isırgan otu uçucu yağlarunın oyuk agar test sonuçlarında Gram pozitif bakteriler üzerinde $(13-30 \mathrm{~mm})$ Gram negatiflere $(8-18 \mathrm{~mm})$ kiyasla daha etkin olmakla birlikte her iki bakteri grubu üzerinde etkili olduğu, pelesenk ve Sedir ağacı (Cedrus libani) uçucu yağlarının test edilen mikroorganizmalar üzerinde inhibisyon zonu oluşturmadığı, diğer test edilen uçucu yağların ise sadece Gram pozitif bakteriler üzerinde etkili olduğu belirlenmiştir. C.albicans inhibisyonunun sadece Bergamot uçucu yağı ile gerçekleştiği $(500 \mu \mathrm{L} / \mathrm{mL}$ ) belirlenmiştir. Pelesenk (Copaifera officinalis) uçucu yağının test edilen mikroorganizmalar üzerinde her hangi bir aktivite sergilemediği saptanmıştır. Bu çalışmanın tespit edilen antimikrobiyal aktiviteler sebebi ile uçucu yağların mikroorganizmalar ile mücadele etmede tamamlayıcı ve alternatif çözümler sunacağı, ayrıca bu çalışmanın uçucu yağların antimikrobiyal etki mekanizmalarının tanımlanmasını konu alan çalışmalara katkı sağlayacağı düşünülmektedir.
\end{abstract}

Anahtar kelimeler: Antimikrobiyal, MIK, Patojen bakteri, Tıbbi bitki, Uçucu yağ

\begin{abstract}
Hospitals are the places where antibiotics for diagnosis and treatment are heavily used thus bacteria and yeast resistance gains and the spread of resistant strains are the most frequent environments. The increase in the number of antibiotic resistant microorganisms adversely affects the infection treatments caused by the microorganism and for this reason, the use of medicinal plants (extracts and essential oils) as an alternative to drugs is becoming widespread.

The aim of this study is to determine the antimicrobial activity of the eleven plant essential oils against the four pathogenic bacteria (Staphylococcus aureus, Bacillus cereus, Escherichia coli, Salmonella spp.,) and yeast (Candida albicans). Broth dilution and well agar techniques were used in this study. The minimum inhibitory concentration (MIC) of Bergamot (Citrus bergamia) and Nettle (Urtica dioica) essential oils was found to be low $(62.5 \mu \mathrm{L} / \mathrm{mL}$ ), against Gram positive bacteria and the antimicrobial activity of eleven plant essential oils tested on Gram negative bacteria was found to be moderate $(125-500 \mu \mathrm{L} / \mathrm{mL})$. In well agar test results, sage (Salvia officinalis), Bergamot, Pinus terebenthinae, Urtica dioica were more effective on Gram positive bacteria $(13-30 \mathrm{~mm})$ than Gram negative bacteria $(8-18 \mathrm{~mm})$ while Copaiba and Cedrus libani were not show any inhibition zone on tested microorganisms and other tested essential oils have antimicrobial activity against only Gram positive bacteria. It was determined that $C$. albicans inhibition occurred only with Bergamot essential oil $(500 \mu \mathrm{L} / \mathrm{mL})$. Rosewood (Copaifera officinalis) essential oil has not been found to exhibit any activity on the all microorganisms tested. It was thought that essential oils will provide complementary and alternative solutions to combat microorganisms due to the antimicrobial activity detected, and this study will contribute to the studies on the identification of antimicrobial action mechanisms of essential oils.
\end{abstract}

Keywords: Antimicrobial, MIC, Pathogen bacteria, Medicinal plant, Essential oil

\footnotetext{
*aa Tuğça BİLENLER; tugca.bilenler@inonu.edu.tr; Tel: ((0544) 40804 80); orcid.org/ 0000-0001-7831-6337

b orcid.org/ 0000-0003-4994-5788
} 


\section{Giriş}

Enfeksiyon hastalıklarının insan ölümlerine sebep olma yüzdesi ülkelerin gelişmişlik seviyesine bağlı olarak değişiklik göstermekle birlikte oldukça yüksektir. Patojen mikroorganizmalar arasında antimikrobiyallere karşı direncin yaygınlaşması mikrobiyal hastalıkların tedavisinde ciddi tehdit oluşturmaktadır. Gelişen bu olumsuz eğilim enfeksiyon hastalılarının tedavisinde ya da önlenmesinde yeni stratejilere ihtiyaç duyulmasına neden olmuştur (Maurice vd., 1990). Dirençli olan ve/ya da olmayan mikroorganizmalar ile mücadele etmede doğal ürün kaynağı olarak bitki ekstraktlarının ve uçucu yağlarının kullanımı alternatif çözümler sunmaktadır. Dünya Sağlık Örgütü (WHO) raporlarına göre dünya nüfusunun önemli bir kısmı öncelikli sağlı hizmetinde geleneksel tedavi uygulamalarını kullanmaktadır. Doğal organik bileşenlerin önemli kaynağı olan tıbbı ve aromatik bitkiler tamamlayıcı tıpta önemli bir yer tutmaktadır (Prabuseenivasan vd., 2006). İnsanlığın ilk çağlarından itibaren tedavi amaçlı kullanılagelen tıbbi bitkilerin yapılarında barındırdığı zengin biyo-moleküller sayesinde, sentetik ilaçlara kıyasla yan etkilerinin da daha az olması nedeni ile mevcut antimikrobiyallere alternatif olabileceği bildirilmektedir (Faydalıŏlu ve Sürücüoğlu, 2011). Günümüzde çeşitli hastalıkların tedavisinde kullanılan maddelerin \%80'i bitkisel kökenlidir. Bitkiler, büyük bir kimyasal çeşitlilik ve biyoaktivite sağlar, bunun araştırılması yüzlerce farmasötik ilacın gelişmesine yol açmıştır (Solmaz ve Ata, 2009).

Uçucu yă olarak da isimlendirilen esansiyel yağlar bitkilerin farklı kısımlarından (çiçek, dal, tohum, yaprak, kök ve meyve gibi) distilasyon, ekstraksiyon, ekspresyon ve fermantasyon gibi farklı tekniklerle elde edilen yağımsı sıvılardır. Yaklaşık 3000 uçucu yağ olduğu bilinmekte ve bunların 300'e yakınının ticari olarak satıldığ tahmin edilmektedir (Prabuseenivasan vd., 2006). Uçucu yağların kimyasal yapılarında birden fazla bileşen bulunduğu, fakat majör grubun terpen ve terpenlerin oksijene edilmiş türevlerinden oluştuğu ve söz konusu bu bileşenlerin esansiyel yağlara fonksiyonalite (antimikrobiyal, antioksidan, ant,-proliferatif vb.) kazandırdığ1 bildirilmiştir (Maurice vd., 1990; Prabuseenivasan vd., 2006).

Antibiyotik direncine karşı bir alternatif çözüm sunmak amacı ile kullanılan bitki sayısı oldukça fazladır. Söz konusu bitkiler arasında taşıdığ potansiyel antimikrobiyal aktivite bakımından öne çıkanlar arasında Pinus terebenthinae (çam terebentin), Copaifera officinalis (pelesenk), Salvia officinalis (adaçayı), Cedrus libani (sedir ağac1), Aesculus hippocastanum (at kestanesi), Hypericum perforatum (kantaron), Santalum album (sandal ağac1), Foeniculum vulgare (rezene), Lavandula stoechas (karabaş otu), Urtica dioica (1sirgan otu) ve Citrus bergamia (bergamot) yer almaktadır.

Pinaceae familyası, Pinus cinsine ait olan çam terebentin (Pinus terebenthinae) bitkisinin yağı terebentin ya da çam odununun distilasyonundan elde edilmektedir. Uçucu yağın majör bileşeni (\%90) pinendir (\%60 $\alpha$-pinen ve \%30 $\beta$-pinen). Yağın güçlü antimikrobiyal etkisinin yanı sıra romatizmal ağrılarına karşı, ciltte kan toplayıcı olarak ve veteriner hekimliğinde haricen ağrı kesici, ayrıca balgam söktürücü ve gögüs yumuşatıc1 olarak kullanıldığ (Süzgeç-Selçuk ve Eyişan, 2012). Pelesenk (Copaifera officinalis), Copaifera cinsine ait ağaç gövdelerinden elde edilen şeffaf, sarı ya da açık kahverengi bir sıvıdır (Veiga-Junior ve Pinto, 2002). Pelesenk yağının antimikrobiyal, antienflamatuar, anti-tetanoz, anti-tümör, antiblenoraji ve idrar antiseptik aktivitelerinin yanı sıra bronşit, deri hastalıkları, ülser tedavisinde kullanıldığı rapor edilmiştir (Gomes vd., 2007). Adaçayı (Salvia officinalis) Laminaceae familyasına ait bir bitki olup, kurutulmuş yaprakları ve uçucu yağı birçok yiyecek ve içeceklerde aroma verici olarak kullanılmaktadır. Bitkinin antibakteriyal, fungustatik, virüstatik, damar büzücü ve antihidrotik gibi pek çok biyolojik aktiviteye sahip olduğu bildirilmiştir (. Keshavarz vd., 2010). Pinaceae familyası, Cedrus cinsine ait olan Sedir ağacı (Cedrus libani) uçucu yağının antifungal, antibakteriyal, antiviral, antienflamatuar aktivite sergilediği rapor edilmiştir (Derwich vd., 2010). Aesculus hippocastanum L. yaygin olarak at kestanesi olarak bilinen yenilebilir kestane (Castanea sativa Mill) ile sadece isim benzerliği olan bit bitkidir. At kestanesi meyveleri, yaprakları ve kabukları karbonhidratlar, saponinler, tanenler, flavonoidler, fenolikler bakımından zengindir (Colak vd., 2017). At kestanesi bitki ekstraktının gida kaynaklı bakterilere karşı antimikrobiyal etkinliğini belirlemek için yapılan çalışmada test edilen tüm bakterilere, özellikle de tüm Gramnegatif bakterilere karşı yüksek antimikrobiyal aktivite gösterdiği belirlenmiştir (Bonomo vd., 2004). Clusiaceae familyas1, Hypericum cinsine ait olan kantaron (Hypericum perforatum L) ekstraktının özellikle Gram pozitif bakteriler üzerinde antibakteriyal etki sergilediği 
belirtilmiştir (Reichling vd., 2001). Santalaceae familyasından olan sandal ağac1 (Arbutus andrachne), hoş kokulu ve tropik bir ağaçtır. Bitkinin kuvvetli antioksidan etkisinin yanı sira, çeşitli mikroorganizmalar üzerinde oldukça güçlü antimikrobiyal aktivite sergilediği saptanmıştır (Faydalıŏlu ve Sürücüoğlu, 2011). Rezene (Foeniculum vulgare Miller), Apiaceae familyasına ait bir bitki olup, geleneksel tıpta uzun bir bitkisel kullanım geçmişine sahiptir. Geleneksel olarak rezene tohumu antiinflamatuar, analjezik, karminatif, diüretik ve spazm önleyici ajanlar olarak kullanılır (Anwara vd., 2009). Lamiaceae familyasından olan karabaş otu (Lavandula stoechas) L., aromatik bir bitkidir. Antiseptik, antimikrobiyal ve yara iyileştirici etkilerinin yanı sıra bir çak hastalığın tedavisinde yüzyıllardır kullanılmaktadır (Öztürk, 2005). Urticaceae familyasina ait olan 1sirgan otu (Urtica dioica) farmakolojik açıdan çok önemli aktiveler (antioksidan, antiinflamatuar, antiülser, anti kolit, antiviral, antikanser, antibakteriyel ve antifungal) sergilemektedir (Bhuwan, 2014). Rutaceae familyasına ait olan bergamot (Citrus bergamia) uçucu yağının güçlü antimikrobiyal etki sergilediği rapor edilmiştir (Pessini, 2003).

\section{Amaç}

Patojen mikroorganizmaların direnç kazanımları ve direncin yaygınlaşmasındaki hız nedenleri ile mikroorganizmalar ile mücadele etmede zorlu bir süreç başlamıştır. Tıbbi değerliği olan bitkiler bu süreçte alternatif ve tamamlayıcı roller üstlenmeleri bakımından dikkat çekmektedir. Bitkilerin sekonder metaboliti olan uçucu yağların antimikrobiyal etkileri geçmişten günümüze yaygın bir uygulama alanına sahiptir. Uçucu yağların üretimi evsel ölçekte oldukça zor bir işlem olduğundan, elde edinimlerinde genellikle ticari olarak satın alma yolu izlenmektedir. Bu nedenlerle çalışmadaki amacımız, ticari olarak satılan ve pek çok kişinin rahatlıkla erişebileceği tıbbi değerliği olan uçucu yağların hastane patojenleri üzerindeki etkilerini belirlemek ve dolayısı ile kontrollü koşullarda alınan bilgiler ışığında söz konusu yağların daha güvenli ve etkin kullanımlarını sağlamaktır.

\section{Gereç ve Yöntem}

\subsection{Kimyasallar}

Aksi belirtilmedikçe çalışmada kullanılan tüm kimyasal standart ve solventler Sigma-Aldrich'ten (Steinheim, Germany) temin edilmiştir.

\subsection{Uçucu Yağlar}

On bir farklı uçucu yağ Malatya'da yöresel bir marketten temin edinilmiştir. Söz konusu uçucu yağlar literatür taraması ve geleneksel tıpta kullanımları temelinde seçilmiştir. Kullanılan yağların saflık derecesi \%98'den daha fazladır.

\subsection{Test organizmaları ve büyüme koşulları}

Antimikrobiyal aktivite testlerinde kullanılacak mikroorganizmalar Malatya, İnönü Üniversitesi Turgut Özal Tıp Merkezi (TÖTM), Mikrobiyoloji Laboratuvarından temin edilmiştir. İki Gram pozitif (Staphylococcus aureus, Bacillus cereus), iki Gram negatif (Escherichia coli, Salmonella spp.,) bir maya Candida albicans) kullanılmıştır. Mikroorganizmalar testlerde kullanılıncaya kadar uygun agar ortamlarında (Bakteriler için, Brain Hearth Infusion Agar (Merck Darmstadt, Germany), maya için Potato Dextrose Agar (Merck Darmstadt, Germany) $+4^{\circ} \mathrm{C}$ 'de bekletilmiş, antimikrobiyal testlerde stok kültür olarak kullanılmıştır.

Testlerde kullanılacak mikroorganizmaların aktif taze kültürleri (gece kültürü) hazırlanmıştır. Bu amaçla bakteriler için Mueller Hinton Broth (Merck Darmstadt, Germany), maya için Sabouraud Dextrose Broth (Merck Darmstadt, Germany) $10 \mathrm{~mL}$ içeren tüplere mikroorganizma ekimleri yapılmış ve bakteriler $+37^{\circ} \mathrm{C}$ 'de 24 saat, maya $+27^{\circ} \mathrm{C}$ 'de 48 saat inkübasyona bırakılmıştır. İnkübasyon süresi sonunda mikroorganizma yükü steril fizyolojik tuzlu su (FTS) yardımı ile $10^{6}$ koloni oluşturma birimi (KOB)/mL olacak şekilde seyreltilmiştir.

\subsection{Antimikrobiyal aktivite testleri}

\subsubsection{Broth Dilüsyon yöntemi}

Uçucu yağların antimikrobiyal aktivitesi Pessini vd., (2003) tarafindan önerilen yöntemde bazı değişiklikler yapılarak uygulanmış ve antimikrobiyal aktivite mikroorganizma gelişiminin olmadığ 1 en düşük uçucu yağ miktarı (minimum inhibisyon konsantrasyon, MIK) olarak belirlenmiş̧ir. Uçucu yağların broth ortamında homojen dağılımını sağlamak amacı ile dimetil sulfoksit (DMSO), \%10 (v/v) kullanılmıştır. Böylece \%10 DMSO'lu broth (bakteriler için Mueller Hinton Broth, maya için Sabouroud Dextrose Broth) içeren tüplere her bir uçucu yağın ayrı ayr1 iki katı seri dilüsyonlar 1000'den 3.9 $\mu \mathrm{L} / \mathrm{mL}$ eklenmiştir. Taze aktif kültürleri hazırlanan bakteri ve maya kültürleri her bir test 
tüpüne ayr1 ayr1 $\left(10^{6} \mathrm{kob} / \mathrm{mL}\right) 50 \mu \mathrm{L}$ hacimlerde inoküle edilmiştir. İnokülasyon işlemleri tamamlanan tüpler bakteriler için $+37^{\circ} \mathrm{C}$ 'de 24 saat, maya $+27^{\circ} \mathrm{C}^{\prime}$ de 48 saat inkübasyona bırakılmıştır. Antimikrobiyal testlerle eş zamanlı olarak pozitif ve negatif kontroller yapılmıştır. $\mathrm{Bu}$ amaçla negatif kontrol olarak broth ortamına ilgili mikroorganizma ekimleri yapılmıştır, herhangi bir antimikrobiyal ajan ilavesi yapilmadan inkübasyona birakılan test tüplerinde mikroorganizmaların sağlıklı gelişebildiği belirlenmiştir. Pozitif kontrol olarak standart antimikrobiyal ajanlar (tetrasiklin, ampisilin, gentamisin ve flukonazol) $(100 \mu \mathrm{g} / \mathrm{mL}$ 'den 1.56 $\mu \mathrm{g} / \mathrm{mL}$ 'ye değişen konsantrasyonlarda) kullanılarak mikroorganizmaların herhangi bir dirence sahip olmadığı, antimikrobiyal ajanlar ile inhibe edilebileceği belirlenmiştir.

Antimikrobiyal aktivitenin broth dilüsyon yöntemi ile tespit edilmesinde indikatör olarak $\rho$ iodonitrotetrazolium violet (INT) mikrobiyal gelişim indikatörü olarak kullanılmıştır. Test ortamında yaşamına devam eden mikroorganizma tetrazolium violeti, violet formazana indirgemekte ve renksiz olan test tüpünde bu kimyasal reaksiyon nedeni ile kırmızı renk açığa çıkmaktadır (Eloff, 2001). İnkübasyon süresini tamamlayan test tüplerine $50 \mu \mathrm{L}$ hacminde $(0.2$ $\mathrm{mg} / \mathrm{mL}$ olacak konsantrasyonda steril suda hazırlanan) INT indikatörü ilave edilmiş ve tüpler $30 \mathrm{dk}$ daha inkübasyona bırakılmıştır. İleri inkübasyon süresi sonunda bakteri gelişimi INT dformazan üretimine bağlı olarak açığa çıkan kırmızı renk değerlendirmesi ile belirlenmiş, bakteri gelişiminin olmadığ en düşük uçucu yağ konsantrasyonu MIK $(\mu \mathrm{L} / \mathrm{mL})$ olarak belirlenmiştir.

\subsubsection{Oyuk Agar yöntemi}

Oyuk agar testi Irshad vd., (2012) tarafindan kullanılan yöntemde hafif modifikasyonlar uygulanarak gerçekleştirilmiştir. Aktif taze kültürleri hazırlanan $\left(10^{6} \mathrm{kob} / \mathrm{mL}\right)$ mikroorganizmalar $(250 \mu \mathrm{L})$ içerisinde Mueller Hinton Agar (bakteriler için) ve Sabouraud Dextrose Agar (maya için) bulunduran petri plaklarına steril swap yardımı ile yayma plaka yöntemi ile yayılmıştır. Yüzeyin mikroorganizma solüsyonunu emmesine izin verildikten sonra (15 dk) steril oyuk açıcı kullanılarak (4mm çapında) oyuklar açılmış, açılan oyuklar uçucu yağ ile (50 $\mu \mathrm{L})$ doldurulmuştur. Pozitif kontrol olarak tetrasiklin, ampisilin, gentamisin ve flukonazol $(1 \mathrm{mg} / \mathrm{mL}$ konsantrsyonunda steril suda hazırlanan) kullanılmış, uçucu yağ ile aynı adımlar takip edilerek, $50 \mu \mathrm{L}$ tetrasiklin açılan oyuklara doldurulmuştur. Hazırlanan petri kutuları 2 saat oda sıcaklığında bekletildikten sonra yüzü yukarı doğru inkübatöre yerleştirilmiş, bakteriler için $+37^{\circ} \mathrm{C}$ 'de 24 saat, maya $+27^{\circ} \mathrm{C}$ 'de 48 saat inkübasyona bırakılmıştır, süre sonunda oluşan inhibisyon zon çapları milimetre birimi ile ölçülmüştür.

\section{Bulgular}

On bir bitki uçucu yağının 5 mikroorganizmaya karş1 belirlenen antimikrobiyal aktivitesi Tablo 1 ve 2'de verilmiştir. Seçilen uçucu yağların oldukça geniş bir aralıkta antimikrobiyal aktivite sergilediği görülmektedir. Pessini vd., (2003) yaptıkları çalışmalarında, antimikrobiyal ajanın MIK değeri $100 \mu \mathrm{g} / \mathrm{mL}$ den düşükse iyi bir antimikrobiyal, $100-500 \mu \mathrm{g} / \mathrm{mL}$ aralığında ise orta dereceli bir ajan, $500-1000 \mu \mathrm{g} / \mathrm{mL}$ aralığında ise zayıf bir antimikrobiyal aktiviteye sahip olduğu, $1000 \mu \mathrm{g} / \mathrm{mL}$ 'den yüksek ise herhangi bir antimikrobiyal etkiye sahip olmadığını rapor etmiş̧lerdir. Test edilen uçucu yağlar arasında bergamot ve isırgan otu uçucu yağının Gram pozitif bakterilere karş1 $(62.5 \mu \mathrm{L} / \mathrm{mL}, \mathrm{MIK})$ iyi; Gram negatif bakterilere karşı ise orta dereceli (250-500 $\mu \mathrm{L} / \mathrm{mL}$, MIK) bir antimikrobiyal etki sergilediği ifade edilebilir. Adaçay1, çam terebentin, rezene, sedir ağacı uçucu yağları test edilen tüm mikroorganizmalara karşı orta dereceli (125-500 $\mu \mathrm{L} / \mathrm{mL}$, MIK) bir antimikrobiyal etki sergilerken, pelesenk uçucu yağının test edilen beş mikroorganizmaya karş1 herhangi bir etki göstermediği (>1000 $\mu \mathrm{g} / \mathrm{mL}$, MIK) belirlenmiştir.

On bir bitki uçucu yağına karşı yapılan hassasiyet siralamasında ilk sirada Gram pozitif bakteriler, ikinci sirada Gram negatif bakteriler ve son sirada maya yer almaktadır. Mayanın bergamot uçucu yağı dışında diğer uçucu yağlara karşı oldukça dirençli olduğu Tablo 1'de görülmektedir. Ayrıca karabaş otu uçucu yağı dişında test edilen tüm uçucu yağlara karşı en hassas mikroorganizmanın B.cereus olduğu görülmektedir.

Testte negatif kontrol olarak yer alan tüplerde mikroorganizmaların, $\% 10 \quad$ DMSO'dan etkilenmeden rahatlıkla yaşayıp çoğaldığı, pozitif kontrol olarak kullanılan üç farklı standart antibakteriyel ve bir antifungal ajanın test edilen bakteriler ve maya üzerinde farklı konsantrasyonlarda (1.56-12.25 $\mu \mathrm{g} / \mathrm{ml})$ inhibitör etkiye sahip olduğu bir başka deyişle test edilen mikroorganizmaların her hangi bir dirence sahip olmadığı belirlenmiştir. 
Tablo 1. On bir bitki uçucu yağının ve standart antimikrobiyallerin broth dilüsyon yöntemi ile minimum inhibisyon konsantrasyonu (MIK)

\begin{tabular}{|c|c|c|c|c|c|c|}
\hline \multirow{3}{*}{\multicolumn{2}{|c|}{$\begin{array}{l}\text { Bitki Uçucu Yağı } \\
(\mu \mathrm{L} / \mathrm{mL})\end{array}$}} & \multicolumn{5}{|c|}{ Mikroorganizmalar } \\
\hline & & \multicolumn{2}{|c|}{ Gram pozitif } & \multicolumn{2}{|c|}{ Gram negatif } & \multirow{2}{*}{$\begin{array}{c}\text { Maya } \\
\text { C.albicans } \\
\end{array}$} \\
\hline & & S.aureus & B.cereus & E.coli & Salmonella & \\
\hline \multicolumn{2}{|c|}{ Ada çayı } & 125 & 125 & 250 & 500 & 1000 \\
\hline \multicolumn{2}{|c|}{ At kestanesi } & 125 & 62.5 & 500 & 500 & 1000 \\
\hline \multicolumn{2}{|c|}{ Bergamot } & 62.5 & 62.5 & 500 & 250 & 500 \\
\hline \multicolumn{2}{|c|}{ Çam terebentin } & 250 & 125 & 500 & 500 & 1000 \\
\hline \multicolumn{2}{|c|}{ Isırgan otu } & 62.5 & 62.5 & 125 & 250 & 1000 \\
\hline \multicolumn{2}{|c|}{ Kantaron } & 500 & 250 & 1000 & 1000 & $>1000$ \\
\hline \multicolumn{2}{|c|}{ Karabaş otu } & 62.5 & 500 & 500 & 500 & $>1000$ \\
\hline \multicolumn{2}{|c|}{ Pelesnek Yağı } & $>1000$ & $>1000$ & $>1000$ & $>1000$ & $>1000$ \\
\hline \multicolumn{2}{|c|}{ Rezene } & 250 & 250 & 500 & 500 & 1000 \\
\hline \multicolumn{2}{|c|}{ Sandal ağacı } & 500 & 62.5 & 1000 & $>1000$ & $>1000$ \\
\hline \multicolumn{2}{|c|}{ Sedir Ağacı } & 500 & 250 & 500 & 500 & $>1000$ \\
\hline \multicolumn{2}{|c|}{ Negatif Kontrol } & $+*$ & + & + & + & + \\
\hline \multirow{4}{*}{$\begin{array}{l}\text { Pozitif Kontrol } \\
\quad(\mu \mathrm{g} / \mathrm{mL})\end{array}$} & Tetrasiklin & 1.56 & 1.56 & 1.56 & 1.56 & $-* *$ \\
\hline & Ampisilin & 3.12 & 6.25 & 12.25 & 6.25 & $-* *$ \\
\hline & Gentamisin & 1.56 & 1.56 & 6.25 & 3.12 & $-* *$ \\
\hline & Flukonazol & $-* *$ & $-* *$ & $-* *$ & $-* *$ & 12.25 \\
\hline
\end{tabular}

*: mikroorganizma gelişmesi var; **: test edilmedi

Testte negatif kontrol olarak yer alan tüplerde mikroorganizmaların, $\% 10 \quad$ DMSO'dan etkilenmeden rahatlıkla yaşayıp çoğaldığ kontrol olarak kullanılan üç farklı standart antibakteriyel ve bir antifungal ajanın test edilen bakteriler ve maya üzerinde farklı konsantrasyonlarda $(1.56-12.25 \mu \mathrm{g} / \mathrm{ml})$ inhibitör etkiye sahip olduğu bir başka deyişle test edilen mikroorganizmaların herhangi bir dirence sahip olmadığ belirlenmiştir.

Prabuseenivasan vd., (2006) yaptıkları çalışmada $7 \mathrm{~mm}$ ve yukarısında belirlenen zon ölçümlerini pozitif sonuç olarak tanımlamıştır. Oyuk agar test sonuçlarında on bir bitki uçucu yağının ikisi (pelesenk ve sedir ağacı) dışında kalan tüm bitki uçucu yağlarının en azından bir mikroorganizmaya karş1 antimikrobiyal etki sergilediği belirlenmiştir (Tablo 2). Adaçayı, bergamot, çam terebentin ve isırgan otu hem Gram pozitif hem de Gram negatif bakterilere karş1 antibakteriyal etki göstermiş olup, kantaron, karabaş otu, rezene ve sandal ağacı uçucu yağlarının sadece Gram pozitif bakteriler üzerinde etkili olduğu, Gram negatifler üzerinde herhangi bir etki göstermediği belirlenmiştir. Diğer taraftan, oyuk agar yönteminde test edilen on bir bitki uçucu yağının hiç birinde C.albicans'a karşı antifungal etki saptanamamıştır.

Tablo 2. Uçucu yağlar ve standart antimikrobiyalin oyuk agar yöntemi ile antimikrobiyal aktivitesi

\begin{tabular}{|c|c|c|c|c|c|}
\hline \multirow{3}{*}{$\begin{array}{c}\text { Bitki Uçucu Yağı } \\
\text { (mm) }\end{array}$} & \multicolumn{5}{|c|}{ Mikroorganizmalar } \\
\hline & \multicolumn{2}{|c|}{ Gram pozitif } & \multicolumn{2}{|c|}{ Gram negatif } & \multirow{2}{*}{$\begin{array}{c}\text { Maya } \\
\text { C.albicans }\end{array}$} \\
\hline & S.aureus & B.cereus & E.coli & Salmonella & \\
\hline Ada çayı & 28 & 30 & 18 & 13 & $-*$ \\
\hline At kestanesi & 12 & 20 & - & - & - \\
\hline Bergamot & 21 & 20 & 8 & 14 & \\
\hline Çam terebentin & 13 & 21 & 8 & 8 & - \\
\hline Isırgan otu & 15 & 17 & 10 & 9 & \\
\hline Kantaron & 7 & 8 & - & - & - \\
\hline Karabaş otu & 21 & 8 & - & - & - \\
\hline Pelesnek Yağ & - & - & - & - & - \\
\hline Rezene & 13 & 15 & - & - & - \\
\hline Sandal ağacı & 8 & 37 & - & - & - \\
\hline Sedir Ağacı & - & - & - & - & - \\
\hline Negatif Kontrol & + & + & + & + & $+* *$ \\
\hline Pozitif Kontrol $\quad$ Tetrasiklin & 40 & 34 & 30 & 20 & $-* * *$ \\
\hline
\end{tabular}

*:inhibisyon zonu oluşmamıştır; **: mikroorganizma gelişmesi var, ${ }^{* * *}$ : test edilmemiştir

Broth dilüsyon yönteminde elde edilen sonuçlara benzer olarak, oyuk agar testinde, bitki uçucu yağlarına karşı Gram pozitif bakterilerden Gram negatiflere kıyasla daha yüksek hassasiyet gösterdiği, Gram pozitif bakterilerden S.aureus'un (7-28 mm) B.cereus'dan (8-37mm) daha dirençli olduğu belirlenmiştir. Oyuk agar test koşullarında da negatif ve pozitif kontrol sonuçlarından test 
edilen mikroorganizmaların yarı katı besiyeri ortamında sırası ile sağlıklı yaşadığı ve farklı zon çaplarına (20-40 mm) sahip olmaları nedeni ile herhangi bir dirence sahip olmadikları bulgusu elde edilmiştir.

\section{Tartışma ve Sonuçlar}

Bitki uçucu yağları yüzyıllardır gıdaların korunması, eczacilık, tıp ve doğal tedavi edici olarak farklı alanlarda yaygın kullanılmaktadır. Sağlık alanında kaliteyi arttırmak için geleneksel tıpta kullanılan uçucu yağların bilimsel olarak incelenmesi oldukça elzemdir. Esansiyel yağlar yeni antimikrobiyal ajanların geliştirilmesi noktasında (özellikle patojen bakterilere karşı) yüksek potansiyele sahiptir. Çalışmamızda, on bir bitki uçucu yağın (pelesenk uçucu yağı hariç) beş hastane patojenine karşı farklı oranlarda antimikrobiyal aktivite sergilediği belirlenmiştir.

Literatürde yer alan çalışmada söz konusu uçucu yağların farklı mikroorganizmalara karşı değişken skalada antimikrobiyal aktivite sergilediği rapor edilmiştir. Araştırma bulgularımız ile uyumlu olarak; Pesavento vd., (2015) yaptığı bir çalışmada adaçayı uçucu yağına karşı S.aureus 'un en hassas (22.7 mm zon çapi) bakteri olduğu, Campylobacter jejuni'nin ise test edilen grup içinde en dirençli $(9 \mathrm{~mm})$ bakteri olduğu bildirilmiştir. Al-Howiriny vd., (2003) adaçay1 uçucu yağının antimikrobiyal aktivitesinin Gram negatif bakterilere kıyasla Gram pozitif bakteriler üzerinde çok daha yüksek olduğunu bildirmiştir. sekiz mikroorganizmaya karşı at kestanesinin antimikrobiyal etkisinin incelendiği çalışmada, S.aureus ve B.cereus'un inhibisyon zonunun E.coli'den daha yüksek olduğunu ve en yüksek hassasiyetin L. monocytogenes'e ait olduğu bildirilmiştir (Öztürk 2017). At kestanesinin sergilediği antimikrobiyel aktivitenin bileşiminde yer alan flavonoidlerden kaynaklandığı rapor edilmiştir (Harborne ve Baxter, 1993).

Bergamot uçucu yağının farklı Listeria türleri üzerindeki antimikrobiyal etkisini disk difüzyon metodu ile inceleyen Marotta vd., (2016) 3 suşun hassasiyetinin zayıf, 4 suşun ise yağa karş1 hassasiyetinin oldukça yüksek (14-20 mm) olduğunu, Keskin ve Toroğlu (2011) bergamot yağının patojen bakteriler üzerinde oldukça yüksek antimikrobiyal etki sergilediğini, disk difüzyon metodu ile bergamot, uçucu yağının antimikrobiyal aktivitesini test eden Fisher ve Phillips, (2006) bergamot uçucu yağının Gram pozitif bakteriler üzerinde (S.aureus 46 , B.cereus $36 \mathrm{~mm}$ ), Gram negatif bakterilere (E.coli 24,
C.jejuni $23 \mathrm{~mm}$ ) kıyasla daha yüksek inhibisyon zon çap1 oluşturduğu bildirilmiş, ve bu aktivitenin bileşiminde yer alan Limonen (\%45) ve Linaloolden (\%15) kaynaklandığını rapor etmişlerdir. Aumeeruddy-Elalfi vd., (2015) çam terebentin uçucu yağı MIK değerini S.aureus'a karş1 $0.25 \mathrm{mg} / \mathrm{mL}$ Acinetobacter'e karş1 16 $\mathrm{mg} / \mathrm{mL}$ olarak bildirmiş ve bitkinin Gram pozitif bakteriler üzerinde aktivitesinin daha kuvvetli olduğunu ifade etmişlerdir. Saenz vd., (2004) çam terebentin uçucu yağının Gram negatif bakterilere kıyasla Gram pozitif bakteriler üzerinde daha etkili olduğunu ve ayrıca potansiyel antiseptik ajan olarak kullanılabileceğini bildirmişlerdir.

Sedir ağacı yağının antimikrobiyal aktivitesini inceleyen Ery1lmaz vd., (2016) test edilen 7 mikroorganizmaya karşı bitkinin etki göstermediğini bildirmiş, Kızıl vd., (2002) ise konsantrasyona bağlı olarak etki gösterdiğini ayrica Gram pozitif bakterilerin Gram negatif bakterilere kıyasla daha hassas olduğunu rapor etmiştir. Kantaron ekstraktının Gram pozitif bakteriler üzerinde $(0.1-1.0 \mu \mathrm{g} / \mathrm{mL})$ Gram negatiflere $(400 \mu \mathrm{g} / \mathrm{mL})$ göre daha yüksek aktivite gösterdiği bildirilmiştir (Reichling vd., 2014). Dall Agnol vd., (2003) altı farklı kantaron türünün antimikrobiyal aktivitesini inceledikleri çalışmalarında, S.aureus'un E.coli ve S.cerevisiae' a kıyasla daha hassas olduğunu ve ayrica söz konusu antimikrobiyal etkinin bileşimde önemli yüzdelik alana sahip olan tanin, flavonoid ve fenolik asitlerden kaynaklandığ rapor etmişlerdir. Gülçin vd., (2004) 1sırgan otunun 9 bakteri, 1 mayaya karş1 güçlü antimikrobiyal aktivite sergilediğini, Behbahani vd., (2013), karabaş otu ekstraktının Gram pozitif bir bakteri olan $S$. aureus üzerinde güçlü bir antimikrobiyal etkiye sahip olduğunu, Kırmızibekmez vd., (2009) karabaş otu antimikrobiyal aktivitesinde etkili olan bileşenlerinin alfa-fenkon(\%41.9), 1.8-sineol (\%15.6) ve kamfor $(\% 12.1)$ olduğunu bildirmişlerdir. Jirovetz vd., (2006) üç farklı sandal ağacı türünün antimikrobiyal aktivitesini incelemiş ve Gram pozitif bakteriler üzerinde daha etkili olduğunu vurgulamıştır.

Ayrıca, çalışmamızda test edilen mikroorganizma grupları arasında bitki uçucu yağlarına karşı Gram pozitif bakterilerin hassasiyetlerin, Gram negatiflerden daha fazla olduğu belirlenmiştir. Şengün ve Öztürk (2018) bu durumu Gram pozitif bakterilerin hücre duvar yapısinda bulunan lipoteikoik asitlerin lipofilik yapıdaki uçucu yağların hücreye girişini kolaylaştırmasından ve ayrıca Gram negatif bakterilerin hücre duvar 
bileşeni olan lipopolisakkarit tabakasının lipofilik karakterdeki yapıların hücre girişini sınırlaması ile açıklamıştır.

Tibbı değerliği olan uçucu yağların mikroorganizmalarla mücadele etmede yaygın kullanımlarına rağmen antimikrobiyal etki mekanizmaları tam olarak tanımlanmamıştır. Yapılan çalışmalarda bahsi geçen etki mekanizması ile ilgili farklı yaklaşımlar ileri sürülmüştür; bakteri inhibisyonunun membran bütünlügünün bozulmasından, membranın seçici geçirgen yapısının zarar görmesi nedeni ile hücre içeriğinde (molekül ve iyonlar) kayıpların yaşanmasından, uçucu yağ bileşiminde yer alan sekonder metabolitlerin (fenolik bileşikler) hücre zarında hasara neden olmasindan, hücrenin yaşamsal faaliyetlerinin (enerji üretimi, protein sentezi) yağdan zarar görmesinden kaynaklanabileceği iddia edilmektedir (Beyza, 2014; Şengün ve Öztürk, 2018).

Sonuç olarak, bu çalışmada antimikrobiyal maddelere karşı kazanılan ve yaygınlaşan direnç sebebi ile daha da zorlaşan patojen mikroorganizma inhibisyonuna alternatif çözümler sunan uçucu yağlardan bazılarının antimikrobiyal kapasiteleri değerlendirilmiştir. Söz konusu çalışmanın moleküler yöntemler ile yapılacak olan uçucu yă antimikrobiyal etki mekanizmalarının tanımlanmasını konu alan diğer çalışmalara katkı sağlayacağını düşünmekteyiz.

\section{Teșekkür}

Bu çalışma İnönü Üniversitesi, Bilimsel Araştırma Projeleri Birimi (BAP) tarafindan 1468 ID numaras1 ve FBA-2018-1468 proje kodu ile desteklenmiştir.

\section{Kaynaklar}

Al-Howiriny, T.A., 2003. Composition and antimicrobial activity of Essential oil of Salvia lanigera. Pakistan Journal of Biological Sciences, 6, 133-135.

Anwara, F., Alia, M., Hussaina, A.I., Shahida, M., 2009. Antioxidant and antimicrobial activities of essential oil and extracts of fennel (Foeniculum vulgare Mill.) seeds from Pakistan. Flavour Fragrance Journal, 24, 170-176.

Aumeeruddy-Elalfi, Z., Gurib-Fakim, A., Mahomoodally, F., 2015. Antimicrobial, antibiotic potentiating activity and phytochemical profile of essential oils from exotic and endemic medicinal plants of
Mauritius. Industrial Crops and Production, 71, 197-204

Behbahani, B.A., Tabatabaei-Yazdi, F., Shahidi, F., Mortazavi, A., 2013. Antimicrobial effects of Lavandula stoechas L. and Rosmarinus officinalis L. extracts on Escherichia coli and Staphylococcus aureus. Science Journal of Microbiology, 2, 15-22.

Beyaz, M., 2014. Esansiyel yağlar: Antimikrobiyal, antioksidan ve antimutajenik aktiviteleri, Akademik Gida,12, 45-53.

Bhuwan, C.J., Minky, M., Ajudhia, N.K., 2014. Pharmacognostical review of Urtica dioica $\mathrm{L}$. International Journal of Green Pharmacy, 1, 201-209.

Bonomo, M.G., Cafaro, C., Russo, D., Calabrone, L., Milella, L., Saturnino, C., Capasso, A., Salzano,G., 2004. Antimicrobial activity, antioxidant properties and phytochemical screening of Aesculus Hippocastanum mother tincture against food-borne bacteria. Letters in Drug Des Discovery, 12, 16-21.

Colak, H., Karaköse, E., Duman, F., 2017. High optoelectronic and antimicrobial performances of green synthesized $\mathrm{ZnO}$ nanoparticles using Aesculus hippocastanum. Environmental Chemical Letter, 15, 547-552.

Dall Agnol, R., Ferrraz, A., Bernardi, A.P., Albring, D., Nör, C., Sermento, L., Lamb,L., Hass, M., von Poser, G., Schapoval, E.E.S., 2003, Antimicrobial activity of some Hypericum species, Phytomedicine, 10, 511-516.

Derwich, E., Benziane, Z., Bozkır, A., 2010. Chemical composition and in vitro antibacterial activity of the essential oil of Cedrus atlantica. International Journal of Agriculture Biology, 12, 381-385.

Eloff, J.N., 2001, Antibacterial activity of Marula (Sclerocarya birrea (A. Rich.) Hochst. subsp. caffra (Sond.) Kokwaro) (Anacardiaceae) bark and leaves. Journal of Ethnopharmacology, 76, 305-308.

Eryılmaz, M., Tosun, A., Tümen, İ., 2016 Antimicrobial activity of some species from Pinaceae and Cupressaceae, Türk Journal Pharmacy Science, 13, 35-40.

Faydalığlu, E., Sürücüoğlu, M.S., 2011. Geçmişten günümüze tıbbi ve aromatik bitkilerin kullanılması ve ekonomik önemi. Kastamonu University Journal of Forestry Faculty, 11, 52 67.

Fisher, K., Phillips, C.A., 2006. The effect of lemon, orange and bergamot Essential oils and their 
components on the survival of Campylobacter jejuni, Escherichia coli 0157, Listeria monocytogenes, Bacillus cereus and Staphylococcus aureus in vitro and in food systems, Journal of Applied Microbiology, 3, 1232-1239.

Gomes, N.M., Rezende, C.M., Fontes, S.P., Matheus, M.E., Fernandes, P.D., 2007. Antinociceptive activity of Amazonian copaiba oils. Journal of Ethnopharmacolgy, 12, 486-492.

Gülçin, G., Küfrevioğlu, I., Oktay, M., Büyükokuroğlu, M.E., 2004. Antioxidant, antimicrobial, antiulcer and Analgesic Activities of Netle (Urtica dioica). Journal of Ethnofarmacology, 90, 205- 215.

Harborne J.B., Baxter H. 1993. Phytochemical dictionary. a handbook of bioactive compounds from plants. Taylor and Francis, London].

Irshad, S., Mahmood, M., Perveen, F., 2012. In-vitro anti-bacterial activities of three medicinal plants using agar well diffusion method. Research of Journal Biology, 02, 1-8.

Jirovetz, L., Buchbauer, G., Denkova, Z., Stoyanova, A., Murgov, I., Gearon, V., Birkbeck, S., Schmidt, E., Geissler, M., 2006. Comparative study on the antimicrobial activities of different sandalwood essential oils of various origin. Flavour and Fragrance Journal, 21,16-21.

Keshavarz, M., Mostafaie, A., Mansouri, K., Bidmeshkipour, A., Motlagh H.R.M., Parvaneh, S., 2010. In vitro and ex vivo antiangiogenic activity of Salvia officinalis. Phytotheraphy Research, 24, 1526-1531.

Keskin, D., Toroğlu, S., 2011. Gıda Kaynaklı Bazı Patojen Bakterilerin Gelişmesini Engelleyen Tıbbi Bitkiler ile Bunların Ekstraktları ve Uçucu Yağlar1. Academic Food Journal, 8, 53-60.

Kırmızıbekmez, H., Demirci, B., Yeşilada, E., Beşer, KH., Demirci, F. 2009. Chemical composition and antimicrobial activity of the Essential oils of Lavandula stoechas L. ssp. Stoechas growing in Turkey. Natural Product Communication, 4, 1001-1006.

Kizil, M., Kizil G., Yavuz, M., Aytekin, Ç., 2002. Antimicrobial activity of resins obtained from the roots and strems of Cedrus libani and Abies cilicia, Applied Biochemistry and Microbiology, 2, 144-146.

Marotta S.M., Giarratana, F., Parco, A., Neri D., Zilino, G., Gluffride, A., Panebianco, A., 2016, Evaluation of the antibacterial activity of bergamot essential oil on different Listeria monocytogenes strains, Italian Journal of Food Safety, 5, 6176-6182.
Maurice, M.I., Angela, R.D., Chiris, O.O., 1990. New antimicrobials of plant origin. Perspectives on new crops and new uses, 8, 457-460.

Öztürk, B., Konyalıŏlu, S., Kantarc1, G., Çetinkol, D., 2005. İzmir yöresindeki yabani Lavandula stoechas L. subsp. stoechas taksonundan elde edilen uçucu yağın bileşimi, antibakteriyel, antifungal ve antioksidan kapasitesi', Anadolu Ege Tarımsal Araştırma Enstitüsü Dergisi,1, 6172.

Öztürk, Ö., 2016. Antibacterial and antifungal effects of the leaf, seed, seed coat and fruit capsule of Aesculus hippocastanum (Sapindaceae) extracts, Acta Biologica Turcica, 30, 20-23.

Pesavento, G., Calonico, C., Bilia, A.R., Barnabei, M., Calesini, F., Addona, R., Mencarelli, L., Carmagnini, L., Di Martino, M.C., Lo Nostro, A., 2015. Antibacterial activity of Oregano, Rosmarinus and Thymus essential oils against Staphylococcus aureus and Listeria monocytogenes in beef meatballs, Food Control, 54:188-199.

Pessini, G.L., Filho, B.P.D., Nakamura, C.V., Cortez, D.A.G., 2003, Antibacterial activity of extracts and neolignans from Piper regnellii (Miq) C.DC.var.pallescens (C. DC.) Yunck. Memo 'rias do Instituto Oswaldo Cruz, 98, 1115-1120.

Prabuseenivasan, S., Jayakumar, M., Ignacimuthu, S., 2006. In vitro antibacterial activity of some plant Essential oils. Biomedical Central, 6, 3945.

Reichling, J., Weseler, A., Saller, R., 2001. A current review of the antimicrobial activity of Hypericum perforatum. Pharmacopsychiatry 34, 116-118.

Saenez, P., Tornos, M.P., Alvarez, A., Fernandez, M.A., Garcia, M.D., 2004. Antibacterial activity of essential oils of Pimenta racemosa var. terebinthina and Pimenta racemosa var. grisea, Fitoterapia, 75, 599-602.

Solmaz, E.S., Ata, E.P., 2009. Adverse Effects of Herbal Medicines and Products. Türk Hijyen ve Deneysel Biyoloji Dergisi, 66, 133-141.

Süzgeç-Selçuk, S., Eyisan, S., 2012. Review: Türkiye'deki eczanelerde bulunan bitkisel ilaçlar. Journal of Marmara Pharmacy, 16, 164180.

Şengün, İ.Y., Öztürk, B., 2018. Bitkisel kaynaklı bazı doğal antimikrobiyaller, Anadolu Üniversitesi Bilim ve Teknoloji Dergisi C-Yaşam Bilimleri ve Biyoteknoloji, 7, 256-276.

Veiga-Junior, V.F., Pinto, A.C., 2002. The Copaifera L. genus. Quim Nova, 25, 273-286. 